\title{
Ueber die Behandlung der Tuberkulose mit
} Marmorekserum und Neutuberkulin (Bazillenemulsion) nebst einigen Ausblicken in die Zukunft der Tuberkulosebekämpfung.

Von Dr. Max Elsaesser, Spezialarzt fur Lungenkranke und Oberarzt des stadtischen Spitals fur Lungenkranke in Mannheim.

Bei der noch unentschiedenen Streitfrage, ob in der spezifischen Therapie der Tuberkulose der passiven oder der aktiven Immunisierung der Vorzug zu geben sei, fallen Erfahrungen ins Gewicht, welche bei Behandlung mit Marmorekserum und Neutuberkulin (Bazillenemulsion) gemacht werden, denn diese Specifica repräsentieren zurzeit die beiden wichtigsten Heilmittel genannter Immunisierungsmethoden. Nachdem ich vor zwei Jahren zeigen konnte (diese Wochenschrift 1905, No. 48), daß man mit Neutuberkulin die Lungentuberkulose güustig beeinflussen kann, war es mir darum zu tun, auch mit der passiven Immunisierung Heilversuche anzustellen, zumal die Berichte über die Wirksamkeit des Marmorekserums geradezu widersprechend lauteten; ich setze sie als bekannt voraus. Auf meine Bitte stellte mir Herr Marmorek beliebig große Quantitäten seines Serums zur Verfügung, wofür ich ihm zu großem Danke verpflichtet bin. Das Serum wurde teils subkutan in Dosen von $5 \mathrm{ccm}$, teils rectal in Dosen von $5,10,15$ und $20 \mathrm{ccm}$ angewandt; indessen lieb sich die subkutane Methode nicht durchführen wegen der bekannten schmerzhaften Rötungen und Schwellungen an den Spritzstellen, Gelenkaffektionen etc.; die rectale Anwendung geschah im allgemeinen täglich unter Nachspritzen von 10 bis $15 \mathrm{ccm}$ lauwarmen Wassers und wurde fast immer gut und sehr lange vertragen. Ich habe im ganzen 25 Patienten mit dem Serum behandelt, 13 von ihnen entweder vorher oder nachher auch mit Neutuberkulin unter genauer Beobachtung des Krankheitsverlaufs mit l'egelmäßiger Kontrolle des Körpergewichts und vierstündigen Temperaturmessungen. Die in aller Kürze gehaltenen Krankengeschichten sind folgende:

Fall 1. D. L., 19 Jahre alt, III. St. (Einteilung des Kaiserlichen Gesundheitsamtes), Gewicht $54,8 \mathrm{~kg}$. Temperatur bis $38,3^{\circ}$, Drùenfisteln am Hals, Bac. +; vom 24. April bis 9. Mai $190670 \mathrm{ccm}$ MS (Marmorekserum) p. cl. mit nachfolgender leichter Erhöhung der Temperatur bis $38,7^{\circ}$; am 10 . und 13. Mai je $5 \mathrm{ccm}$ subkutan am Oberarm, darauf starke Rötung und Schwellung unterhalb der Spritz- 
stellen, keine Entfieberung, Gewichtsverminderung um $0,75 \mathrm{~kg}$. Draseneiterung besteht weiter; vom 18. Mai bıs 2\%. Dezember NT (Buzillenemulsion), 0,5 bis $70 \mathrm{mg}$, vom $4 \mathrm{Juni}$ an Gewichtszunahme bis $60,3 \mathrm{~kg}$. Fieberabfall am 3. Juli, Schließung der Drisenfisteln, Bac. + , obj. gebessert.

Fall 2. F. J., 29 Jabre alt, III St, Gewicht $62.8 \mathrm{~kg}$, Temperatur bis $37,5 \bullet$, Bac. +; vom 13. September bis 4 . Oktuber $1906115 \mathrm{ccm}$ MS in Dosen von 5 und $10 \mathrm{ccm} \mathrm{p.} \mathrm{cl.} \mathrm{ohne} \mathrm{Temperaturabfall,} \mathrm{am}$ 5. Oktober Anstieg auf $38,2^{\circ}$, Gewichtszunabme bis $63,3 \mathrm{~kg}$. obj. Vermehrung der Rasselgeräusche; vom 16. Oktober bis 10. November NT, 0,3 bis $1 \mathrm{mg}$, Austritt aus dem Spital, keine Be-serung.

Fall 3. H. S., 30 Jahre alt, II - III. St., Gewicht $51.8 \mathrm{~kg}$. Temperatur bis $37,8^{\circ}$, Bac. +; rom 28. September bis 9. Oktober 1906 $\mathrm{NT}, 0,5$ bis $2 \mathrm{mg}$ ohne Erfolg; vom 24 Oktober bis 14 . Dezember $390 \mathrm{ccm}$ MS in Dosen von $5,10,15$ und $20 \mathrm{ccm}$, ebenfalls ohne Einwirkung auf Temperatur und objektiven Befund, jedoch $\mathrm{Ge}$ wichtszunahme auf $58,6 \mathrm{~kg}$ und Berserung des Allgemeinbefindens; deshalb nochmals Versuch mit NT, 0,1 mg, am 28 Dezember. Reaktion auf $40,2^{\circ}$, kein Abfall, Abbruch der spezifischen Behandlung.

Fall 4. F. S.. 28 Jahre alt, II St., Gewicht $78,2 \mathrm{~kg}$, Temperatur bis $39^{\circ}$, Bac. +; vom 13. September bis 4. Ostober $1906150 \mathrm{ccm}$ MS p. cl in Dosen von 5,10 und $15 \mathrm{ccm}$, leiclites Sinken der Temperatur, Gewichtsabnahme auf $76,4 \mathrm{~kg}$, auch auf 0,5 und $1 \mathrm{mg} \mathrm{NT}$ keine Besserung, Exitus am 27. Januar 1907.

Fall 5. W. T., 22 Jahre alt, III. St., Gewicht $57.2 \mathrm{~kg}$, Temperatur bis $37.7^{\circ}$, Bac. +; vom 16. Januar bis 27 März 1906 NT. 0.3 bis $50 \mathrm{mg}$, am 25 . Januar Fieberabfall, Gewicht $665 \mathrm{~kg}$, von $\mathrm{jt}$ tzt an Abnahme des Appetits und Gewichts mit Verdaclit auf beginnende Darmtuberkulose; vom 23. April bis 23. Juni $1906385 \mathrm{ccm}$ MS p. cl. in Dosen ron 5 und $10 \mathrm{ccrn}$, keine Besserung. Schnerzeu in der Blinddarmgegend, abwechselnd Durchfall und Ver-toplung, Austritt aus dem Spical, objektiv verschlımmert, Gewicht 62.4 kin.

Fall 6. J R., 32 Jahre alt, III. St. Gewicht $53 \mathrm{k} x$, Temperatur bis $39^{\circ}$, Bac. +; vom 5 bis 9. Mai 1906 táglich 5 ccm MIS subkutan an beiden Oberarmen, zunachst ohne lukale Reaktion, an 11. Mai Schüttelfrost, $4^{\left(0.4^{\circ}\right.}$, Rỏtung und schmerzhafte Schwtllung der Stichstellen, am 17. M i Anschwellungr brider H udd- und Kniegelenke; rom 1. August bis 18. Septenıber $19061.50 \mathrm{ccm} \mathrm{MS} \mathrm{n} . \mathrm{cl}$ in Dosen von 5 und $10 \mathrm{ccm}$ unter Gewichtszunahme auf $58.7 \mathrm{kr}$ ohne objektive Besserung, am 21. Septenber Hämoptoe; von $9.0 \mathrm{k}-$ tober 1906 bis 12 . Februar 1907 NT 0,1 bis $60 \mathrm{mz}$; vom 23. Januar an nur noch leichte Temperatursteigerungen bis $37,1^{\circ}$, Austritt, um zu arbeiten, Gewicht $63,3 \mathrm{~kg}$, ubjektıv gebessert.

Fall 7. H. M., 3I Jahre alt, I. St., Gewicht $65,5 \mathrm{~kg}$. Tempera-

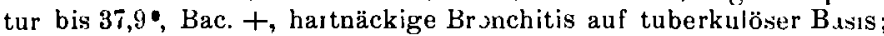
vom 4. bis 12. Dezember $1906^{\circ} 45 \mathrm{ccm}$ MS p. cl. ohne Erfoly; am 14. Dezember $5 \mathrm{ccm}$ subkutan am linken Oberarm mit soforiger starker Rötung und Schwellung der Stichstelle, am 18. handtellergroße, umschritbene Röt ung am linken Vorderarm, dabei Fıberabfill, am 21., 22., 24. je $5 \mathrm{ccm}$ MS p. cl., verweigert weitere $\mathrm{Kly}$ stiere wegen angtblicher häıfıger Le:bschmeszen; vom 2 t. Dez+m ber 1906 bis 10. April 1907 ohne spezfische Behandlung, immer fieberlos, Gewichtszunahme bis $73,8 \mathrm{~kg}$, dabei jedoch aubaltender Husten, Bronchitis beider Lungen, Bac. + , vom 11. April bis 14. Juni $1906 \mathrm{NT}, 0.1$ bis $10 \mathrm{mg} \mathrm{mit}$ baldigem Schwinden der Bronchitis und der Bazillen, tritt aus, um zu arbeiten; obj.: auf beiden Spitzen abgeschwächtes Atmen, nirgends Rhonchi.

Fall 8. F. M., 22 Jahre alt, 11I. St., schwere Erkrankung des linken Unterlappens, Gewicht $64 \mathrm{~kg}$, Temperatur bıs 37.2 , Bac. +; vom 18. Septenıber bis 17. November $1906535 \mathrm{ccm}$ MS in Dosen von 5 und $10 \mathrm{ccm}$ p. cl., vom 10 . Oktober an Temperatur unter $37^{\circ}$ Gewicht am 19. November $69.6 \mathrm{~kg}$, objektiv keine Besserung; vom 19. November bis 11. Dezember NT von 0,1 bis 7 mig, wertere Gewichtszunahme bis auf $70,8 \mathrm{~kg}$, rasche Abnuhme und Trockner werden der Rasselgeräusche im linken Unterlappen. A ustritt, Bac. + .

Fall 9. L. L., 16 Jahre alt, III. St., Gewicht $53,5 \mathrm{~kg}$, Temperatur bis $40^{\circ}$, Bac. +; vom 15. bis 29 . Mai 1906 NT. 05 bis $3 \mathrm{mg}$ ohne Erfolg; vom 5. bis 15. Juni täglich je $5 \mathrm{ccm}$ MS sublutan am Oberschenkel, am 17. Juni schmerzhafte Schwellungen beider Fußgelenke mit umschriebenen Rötungen, kein Tenueraturabfall; vom 18. Juni bis 2. Juli $155 \mathrm{ccm}$ MS in Dosen von 5 und $10 \mathrm{ccm}$, ohne Erfolg, blutige Durchfälle, Abbruch.

Fall 10. M. K, 21 Jahre alt, 11t. St, Gewicht $58 \mathrm{~kg}$, Temperatur bis $38,5^{\circ}$, Bac. +; vom 4 . Mai 1905 bis 9 Februar 1906 NT, 0,5 bis $500 \mathrm{mg}$, vom 8 . Juni an fieberfrei, Gewicht $62,3 \mathrm{~kg}$, wenig objektiv gebessert; anfangs März plötzlicher Eintritt von Fieber mit Schüttelfrösten (akute Mischinfektion); keine Besserung durch Chinin, Aspirin etc., auch niclit durch Wiederaufnahme der NT.Behandlung, anhaltende Gewichtsabnahme; vom 26. April bis 15. Ma $1906165 \mathrm{ccm}$ M.s p. cl. in Dosen von 5 und $10 \mathrm{ccm}$, vom 6. Mai Abnahme des Fiebers, dann 5 fieberfreie Tage; wegen abermaliger
Anstiege bis $37,6^{\circ}$ vom 22 . Mai bis 5 . Juli $410 \mathrm{ccm} \mathrm{MS} \mathrm{p.} \mathrm{cl.} \mathrm{in} \mathrm{Dosen}$ von 5,10 und $15 \mathrm{ccm}$, vom 15 . Juni an völliges Ausbleiben der Schürtelfröste, Temperatur unter $37^{\circ}$, am 8 . und 9. wieder Fieber bis $38,7^{\circ}$, deshalb rom 17 . Juli bis 30 . Alunist wieder $615 \mathrm{ccm}$ MS in Dosen von $15 \mathrm{ccm}$ mit dem Ërfolg, daß zunächst am 14 . Juli, 6 , 16., 22. Aurust an Inten-ität immer mehr abnehmende Fieberanstiege erfolgten mit völlig fieberfreien Intervallen, dann blieb die Temperatur abnorm niedrıg. überstieg kaum einmal 36"; Allyemeinbefınden immer schlecht, Sinken des Gewichts auf $56 \mathrm{~kg}$, keine objektive Besserung, Austritt, baldiger Exitus zu Hause.

Fall 11. L. J., $2 \pm$ Jahre alt, II.-III. St., Gewicht $61 \mathrm{~kg}$, Temperałur bis $37.2^{\circ}$, Bac. +; rom 5.-20. Juni $190635 \mathrm{ccm}$ MS in Dosen ron $5 \mathrm{ccm}$ subkutan am Oberschenkel mit nur geringer lokaler Reaktion, jedoch Temperatursteigerungen bis 33.2 ${ }^{\circ}$, Siuken des Fewichts auf $60.5 \mathrm{~kg}$. Am 22 Juni Hamoptoe; vom 6. Juli bis 12. Oktober NT, $0,3-50 \mathrm{mg}$, Abfall der 'T'emperatur unter $37^{\circ}$, am 28. Juli bleibende Eutfieberung, Gewichts7unahme anf $65,9 \mathrm{~kg}$, am 18. Oktober in die Heilstätte, objektiv gebessert, Bazillen nur noch Splitter.

Fall 12. A. K., 37 Jahre alt, III. St, Gewicht $63.1 \mathrm{~kg}$, Tem-

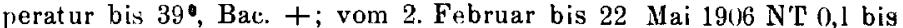
$20 \mathrm{mg}$ ohne Erfolg; vom 29. Mai bis 17. Juli $420 \mathrm{ccm}$ MS in Dosen von 10 und $15 \mathrm{ccm}$, ohne Erfolg, Exitus.

Fall 13 W. B.. 23 Jahre alt, Il. St., Gewicht $58.5 \mathrm{~kg}$, Tem. peratur b/s $38^{\circ}$, Bac. +; vom 11 Aprul bis 20 Angust $190.5 \mathrm{NT} 0,5$ bis $20 \mathrm{mg}$. voin 20. April an lieberloc, oline objektive Bescerung. Gewirhtsabnahme anf $53 \mathrm{~kg}$; zweite $\mathrm{N} \Gamma-K u r$ vom 1 . Márz bis 22 . April 1906, 1-8 ng, abermals ohne Erfulir; vom 27. April bis 8. August $785 \mathrm{ccm}$ MS p. cl in Dusen von 5, 10 und $15 \mathrm{ccm}$; nach den ersten Dosen von 15 ccın Häınoptoe; tritt aus mit Gewicht von $55 \mathrm{~kg}$, objektiv nicht gebessert.

Fall 14. M. S., 33 Jahre alt. II. St., Gewicht 46 kg, Temperatur bis 37,80, Bac +; vom 30. Mai (zwei Tage nach Eintritt ins Spital) bıs 27. Juni $1906260 \mathrm{ccn}$ MS p. cl. in Dusen von $10 \mathrm{ccm}$. Gewichtszunahne auf $49.6 \mathrm{k}$, vom 3 . Juni an fieberlos, objektiv leichte Besserung. Heilstatte.

Fall 1J. E. B, 19 Jahre alt, II. St., Gewirht $53.1 \mathrm{~kg}$, Temperatur bis $37,5^{\circ}$, Bac. +; voln 11.-15. Mai 1906 drei Doven MS subkutan anı Oberdım a $5 \mathrm{ccm}$. am 18. Mai diffuse, juckende Rötung an den Spritzstellen. kein Ti mperaturabf dl; vom 22. Mai bis 8 Juni $12{ }^{\prime} \mathrm{ccm}$ IIS p. cl. jmmer Fieber bis $37.6^{\circ}$; abeımalıger Versuch der subkutanen Applikation: am 9. und 13. Juui je $5 \mathrm{ccm}$ mit abermaliger schmerzhafter Rotungr und Schwellung der Stichstellen; vom 19. Juni bis 1 . A ugust $375 \mathrm{ccm} \mathrm{MS} \mathrm{p.} \mathrm{cl.} \mathrm{in} \mathrm{Dosen} \mathrm{von} 5$ und $10 \mathrm{ccm}$ vom 10. Juni ab neeist fieberlos, objektiv leichte Besserung, Gewicht $59,9 \mathrm{~kg}$, Heilstätte.

Fall 16. W. E., 39 Jahre alt, IlI St, Gewicht $65.1 \mathrm{~kg}$, Temperatur bis 37.9", Bac +; an 8 . Juni $19065 \mathrm{ccm}$ Ms subkutan am Oberschenkel, darauf 39.1", heftige Kopfschmerzen, Schmerzen im ganzen Bein, besonders in den Gelenken; an 12. 14. und 18. Jini je weitere $5 \mathrm{ccm}$ subkutan ohne Beschwerden, am 20. Jiuni Hämoptoe, immer Fieber; vom 2.3. bis 27. Juni $40 \mathrm{ccm} \mathrm{MS} \mathrm{p.} \mathrm{cl.} \mathrm{in} \mathrm{Do:en} \mathrm{von}$ $10 \mathrm{ccm}$ am 29. Juni starke Hämoptoe, aın 10. Juli nochmals $10 \mathrm{ccm}$ MS p cl, darauf starke Durchfalle, Abbruch, Exitus am 14. August 1906.

Fall 17. K. T., 29 Jahre alt, Ende Juli 1906 plötzlich erkrankt mit Hamoptoe nach vorherigem Wohlsein, II. St., Gewicht $\check{\jmath} 2,5 \mathrm{~kg}$, Temperatur bıs $39,4^{\circ}$, Bac. +; vom 10 . November bis 11 . Dezenuber $1906380 \mathrm{ccm}$ MS p. cl. in Dosen von 5, 10, 15 ind $20 \mathrm{ccm}$, ohne Jegliche Bessernng; Exitus am 23. Dezember. Die Seltion ergab neben alten Erkrankungsherden in beiden Oberlappen frische Aussuat von Tuberkeln im rechten Mittel- und Unterlappen, ebenso auf der Kapsel und im Parencliyin der rechten Niere.

Fall 18. H. G., 22 Jahre alt, II -III. St., Gewicht $59 \mathrm{~kg}$, Tenperatur bis $37, \tilde{\delta}^{0}$, Bac. +; vom 14.-23. September $190665 \mathrm{ccn}$ MS p. cl. in Dosen von 5 und $10 \mathrm{ccm}$, ohne jesliche Besserung.

Fall 19. H H., 30 Jahre alt, II. St., Gewicht $51,7 \mathrm{~kg}$, Temperatur bis $37,5^{\circ}$, Bac. + ; vom 13 . November bis 31 . Dezember 1906 $110 \mathrm{ccm}$ MS p. cl. in Dosen von $5 \mathrm{ccm}$, ohne Enttieberung, welche erst nach Aussetzen der Klystiere eintritt am 8. Jannar 1907; Austritt am 19. Februar, objektiv gebessert, Gewicht $63,8 \mathrm{~kg}$, Bdc. +.

Fall 20. E. H., III. St., Gewicht $41.4 \mathrm{~kg}$, fieberlos, Bac. +; vom 14. November bis 13. Dezember $1906160 \mathrm{ccm} M S$ p. cl. in Dosen von 5 und $10 \mathrm{ccm}$; darauf vom 3. Dezember an Fieber. rapider Verlauf, Exitus.

Fall 21. H. K., 25 Jahre alt, II. St., Gewicht $60,6 \mathrm{~kg}$, Temperatu bis $37,6^{\circ}$, Bac. +; vom 24. April (zehn Tage nach Eintritt ins Spital) bis 27 . Juni $1906415 \mathrm{ccm} \mathrm{MS} \mathrm{p.} \mathrm{cl.} \mathrm{in} \mathrm{Dosen} \mathrm{von} 5$ und $10 \mathrm{ccm}$, wahreuddem zweimal Hämoptoe, vom 8 . Juni an fieberfrei, dann leichte Pleuritis exsudativa. Zunahme des Gewichts auf $61,3 \mathrm{~kg}$, objektiv gebessert, Bac, + , Heilstätte. 
Fall 22. S. P., 29 Jahre alt. III. St, Gewicht $61.8 \mathrm{~kg}$. Temperatur bis $37,8^{\circ}$, Bac. +; vom 26 . Oktober bis 7 . November 1906 $40 \mathrm{crm} \mathrm{MS} \mathrm{p.} \mathrm{cl.} \mathrm{in} \mathrm{Dosen} \mathrm{von} 5 \mathrm{ccm}$; weegen ständiger Durchfälle, die vorher feblten, Abbruch, keine Besserung, Austritt.

Fall 23. J. R, 27 Jahre alt, II. St., Gewicht 66 kg, Temperatur bis $37.3^{\circ}$, Bac. +; vom 8. September bis 4 . Oktober $190620 J \mathrm{ccm}$ MS p. cl. in Dosen von 5 and $10 \mathrm{ccm}$, die Temperatur ist im allgemeineu etwas höher, $37.6^{\circ}$, tritt ungebessert aus, Gewicht $67,1 \mathrm{~kg}$.

Fall 24. B. S., 26 Jahre alt, II. St. Gewicht $50.7 \mathrm{~kg}$, fieberlos, Bac. +; vom 6. August bis 22. September $1906500 \mathrm{ccm}$ MS p. cl. in Dosen von 5, 10, $15 \mathrm{ccm}$, nie Fieber, Gewichtszunahme bis $55,3 \mathrm{~kg}$, Bac. +, objektiv gebersert, Heilstätte.

Fall 25. P. K., 27 Jahre alt. III. St., Gewicht $64,1 \mathrm{~kg}$. Temperatur bis $37.6^{\circ}$, Bac. +; vom 2.-13. August $190655 \mathrm{ccm}$ MS ohne Erfolg. tritt aus.

Ueberblicken wir nun die Resultate, so ergibt sich folgendes:

Von 13 mit NT und MS behandelten Fällen sind $8(2,3$, $4,5.9,10,12,13$ ) weder durch das eine noch das andere spezifische Mittel nachweisbar objektiv gebessert worden; bei fünf von ihnen fand nicht einmal Entfieberung statt $(2,3,4$, $9,12)$, während dies bei zwei $(5,13)$ durch NT und bei drei (7, 8. 10) durch MS der Fall war, jedoch ohne dem Fortschreiten der Tuberkulose Einhalt zu tun; dieses wurde jedoch erreicht in fünf Fällen $(1,6,7,8,11)$ durch NT nach vorheriger vergeblicher Behandlung mit MS. bei Fall 6 allerdings nur in leichtem Grade; das Umgekehrte war nie der Fall, d. h. eine merkliche Besserung durch MS nach vorherigem Versagen von NT. Wir kommen zur Betrachtung der zwölf übrigen, nur mit MS behandelten Fälle; hier stehen fünf gebesserte $(14,15,19,21,24)$ sieben ungebesserten gegenüber $(16,17,18,20,22.23 .25)$; indessen kann nur in einem (21) gesagt werden, daß mit einiger Wahrscheinlichkeit dem MS die Schuld an einem guten Erfolg zugeschrieben werden muB; in den vier anderen Fällen fiel der Beginn der Serumbehandlung mit dem Eintritt ins Spital zusammen, sodal die ja so häufige günstige Wirkung des letzteren nicht ausgeschaltet werden kann, im Fall 19 schwand sogar das Fieber erst nach dem Sistieren der Serumklystiere. Aber auch wenn wir bereit sind, diese fünf Fälle von Besserung dem MS aufs Konto zu setzen, so stehen ihnen im ganzen immer noch 20 ungebesserte, ja verschlimmerte gegenüber. Bei Fall 10 müssen wir etwas verweilen, denn hier hatte entschieden das Serum einen günstigen Einfluß auf Fieber und Schüttelfröste; wir hatten es hier jedoch mit einer akut eingetretenen Mischinfektion zu tun, und diese scheint mir durch den Gehalt des Marmorekserums an Streptococcenantitoxinen so ziemlich beseitigt worden zu sein, während die Tuberkulose ruhig weiterschritt und baldigen Exitus veranlaßte. Sollten nicht vielleicht die Erfolge, die andere Autoren, insbesondere Hoffa, bei der Knochentuberkulose sahen, auf der Wirksamkeit des Serum double beruhen? Man hat es doch gewiß bei lange ejternden Fisteln oft mit einer neben der Tuberkulose noch bestehenden Streptococceninfektion zu tun. Fall 3 lehrt, daB man nicht etwa einen schwachen. zur Tuberkulinbehandlung nicht geeigneten Organismus durch passive Immunisierung dazu vorbereiten kann; ich glaube, daß Maragliano recht hat, wenn er sagt (Berliner klinische Wochenschrift 1906. No. 43), duB auch bei der passiven lmmunisierung die Organzelle des Kranken selbst mitwirken muß zur Bildung von Antituberkulinen; ist dies aber der Fall, so gebe ich der aktiven Methode auf Grund bisheriger Erfahrungen den Vorzug; wer aktiv nicht immunisiert werden kann, kann dies auch passiv nicht, wohl aber umgekehrt. Marmorek empfahl mir besonders, einmal eine frische, wenn auch schwel'e Erkrankung mit seinem Serum zu behandeln, da anderwärts dabei die günstigsten Erfahrungen gemacht worden seien; der Fall 17 spricht das Gegenteil, hier konnte, wie die Autopsie ergab, das Serun die frische Aussaat von Tuberkeln nicht verhindern; ich will nicht sagen, daB es daran schuld war, indessen habe ich einen ungünstigen Einfluß auf das Fieber doch in vier Fällen gesehen $(1,2,20,23)$. und das Auftreten von Hämoptoe in fünf Fällen $(6,11.13,16,21)$ ist immerhin etwas auffallend; ausgesprochene Reaktionen, wie beim Tuberkulin, kommen beim Marmorekserum nicht vor; die subkutane Anwendung, gar drei bis vier Tage hintereinander, wie Marmorek mir riet, ist wegen der geschilderten Serumreaktionen geradezı unmöglich; die rectale Methode ist meist durchführbar, und zwar täglich lange Zeit; Fall 10 bekam in vier Monaten $1220 \mathrm{ccm}$ ohne irgendwelche Reizerscheinungen seitens des Darmes, in den Fällen 7, 9, 16, 22 wurden jedoch die Klystiere weniger gut ertragen.

Nach diesen nicht günstigen Erfolgen bei Lungentuberkulose hat auf mein Ersuchen Herr Medizinalrat Dr. Heuck, dirigierender Arzt der chirurgischen Abteilung des städtischen Krankenhauses, im Einverständnis mit Herrn Marmorek sieben Patienten mit chirurgischer Tuberkulose mittels Serumklystieren behandelt; wie mir der erste Assistenzarzt, Herr Dr. Simon, mitteilte, konnte in zwei von diesen sieben Fällen vielleicht ein günstiger Einfluß des Serums durch Schließung von Fisteln angenommen werden, mit Sicherheit konnte jedoch nicht geschlossen werden, daß die Besserung mit dem Serum in Zusammenhang stand; bei den fünf übrigen konnte man absolut heinen günstigen Einfluß des Serums bemerken.

Auf Frund all dieser Erfahrungen werde ich vorläufig in der Behandlung der Tuberkulose der aktiven Immunisierung auch weiterhin den Vorzug geben. Seit meiner oben erwähnten Veröffentlichung über klinische Erfahrungen mit Neutuberkulin (Bazillenemulsion) habe ich dieses Präparat in vielen mir geeignet erscheinenden Fällen angewandt, und ich halte es von allen Tubertiulinpräparaten für dasjenige, welches am sichersten und schnellsten wirkt; 50 Kranke habe ich mit Perlsuchttuberkulin behandelt und bin zu der Ueberzeugung gekommen, daß es dem Neutuberkulin aus keinem Grunde vorzuziehen ist.

Im ganzen habe ich 353 Patienten mit Neutuberkulin gespritzt; Schroeder (Ztschr. f. Tub. Bd. 8. H. 6, S. 510) wirft mir vor „ich sei voreilig gewesen, ich hätte den Abschluß der Behandlung bei einer größeren Zahl von Fällen abwarten und die Entlassenen mindestens ein Jahr in Beobachtung behalten sollen“. Heute kann ich berichten über 56 ambulant Gespritzte, über deren Befinden ich nach einem Jahr oder länger entweder aus ejgener Anschauung oder durch schriftliche Nitteilung, an deren Zuverlässigkeit zu zweifeln ich keinen Grund habe, mich äußern hann; bei allen Kranken war die Diagnose gesichert durch Tuberkulinreaktion im Verein nit positivem Lungenbefund. Von diesen 56 Patienten waren 21 im ersten, 33 im zweiten und zwei im dritten Stadium; I1 von den iın ersten Stadium Befindlichen sind zurzeit geheilt, klinisch und auf Grund der objektiven Untersuchung, welche teilweise durch andere Aerzte ausgeführt wurde; bei weiteren 8 ist das Leiden znm Stillstand gekommen, die Patienten sind ohne Beschwerden und arbeitsfähig, bei zwei mußte die Kur abgebrochen und Heilstätte beantragt werden. Von den $33 \mathrm{im}$ zwe.ten Stadium Befindlichen wurde bei 20 Stillstand und Arbeitsfähigkeit erreicht, 1 mußte in die Heilstätte und 1 ins Spital geschickt werden, 2 entzogen sich der Behandlung. 6 wurden nur leicht gebessert oder bald rückfällig, und bei 3 trat kein Erfolg ein; dasselbe war der Fall bei den 3 Patienten des dritten Stadiums. Wenn man bedenkt, daß alle diese Patienten nur in einer guten häuslichen Ptlege waren, die bei den Tuberkulinkuren ein unbedingtes Erfordernis ist, und daB sie böchstens am SchluB der Kur noch einen mehrwöchigen Landaufenthalt nahmen, woselbst sie, ebenso wie zu Hause, Liegekuren nach meiner Vorschrift machten, so muB das Resultat, insbesondere im ersten Stadium, als ein überraschend gutes bezeichnet werden; den von Schroeder mir gemachten Vorwurf der Voreiligkeit kann ich demnach in aller Ruhe zurückweisen. Unter den Patienten des zweiten Stadiums befindet sich einer, welcher vom Heilstättenarzt sofort wieder zurückgeschickt war "wegen ausgedehnter, schwerer Tuberkulose beider Lungen, schlechten Allgemeinzustandes und ohne Aussicht auf Erfolg"; der behandelnde Arzt schickte inn mir zur spezifischen Behandlung, und nach achtwöchiger Spritzkur konnte er in die Heilstätte zurückgeschickt werden, von wo er dann nach 13 Wochen mit Erfolg 2 entlassen wurde.

Ich habe bei drei Sektionen von Patienten, die früher mit Neutuberkulin behandelt worden waren und rückfällig wurden, da sie in äußerst schlechten Verhältnissen waren, in den Unterlappen Schwielen gesehen, wie man sie an dieser Stelle sonst niemals trifft; in einem Falle war die Halfte des rechten 
Unterlappens, der seiner Zeit akut erkrankt war, in eine derbe, bindegewebige Masse verwandelt, dies konnte nur durch die spezifische Behandlung veranlaßt sein.

Nach diesen günstigen Erfolgen mit der Bazillenemulsion hatte ich bisher keine Veranlassung, mich um die Zulassung zur Tulasebehandlung zu bewerben; ich stand um so inehr davon ab, als ich einige Patienten in Nachbehandlung bekam, deren Brust mit Inzisionsnarben von Abszessen und teilweise noch uneröffneten Erweichungsherden an den Tulasespritzstellen bedeckt war; niemals habe ich etwas derartiges als Folge der Bazillenemulsion gesehen.

Die besten Resultate erreicht man mit der Tuberkulinkur, wie aus obigen Zahlen ersichtlich ist, im ersten Stadium; es ist beim Tuberkulin nicht anders als bei dor Heilstätte: im latenten und im ersten Stadium können Heilungen erzielt werden, im zweiten und dritten Stadium nur ein Stillstand mit späteren Rückfällen. Leider wird noch immer seitens der meisten Aerzte die Diagnose des ersten Stadiums zu spät gestellt; wer auf Bazillen im Sputum wartet, bis er die lichtige Behandlung beginnt, hat die Zeit der möglichen Erfolge in der Therapie bereits verstreichen lassen. Ebenso wird niemals ein Arzt Freund der Tuberkulinbehandlung werden, wenn er sie erstmals dann versucht, wenn feuchtes, klingendes Rasseln, sei es auch auf die Spitzen beschränkt, bereits das dritte Stadium anzeigt; je seltener diese Fehler werden, desto günstiger gestaltet sich auf Grund der spezifischen Behandlung der Ausblick in die Zukunft der Tuberkulosebekämpfung; eine große Anzahl von latenten und ersten Stadien, welche aus irgendwelchem Grunde heute in die Heilstätten nicht aufgenommen werden kann, hat Aussicht auf Heilung durch die häusliche spezifische Behandlung unter Zuhilfenahme oben angeführter weiterer therapeutischer Maßnahmen. Ferner kann ein großer Teil der noch besserungsfähigen zweiten und dritten Stadien diese Besserung erreichen in besonderen Tuberkulosekrankenhäusern der Städte, welche, in peripherischer, gcsunder Lage errichtet und mit allen Einrichtungen der physikalischdiätetischen Heilmethode versehen, in Verbindung mit der spezifischen Behandlung imstande wären, die Heilstätten in bedeutendem Maße zu entlasten. Wenn in solchen billigen Volks sanatorien die oft so lange Wartezeit von den ersten Stadien schon in spezifischer Behandlung verbracht wird, so wird be Vielen eine Heilstättenkur von 8 bis 10 Wochen gegen 13 Wochen jetzt genügen und auf diese Weise eine weitere Entlastung der Heilstättten eintreten. Wenn diese einmal alle das Tuberkulin in ihren Heilschatz aufgenommen haben, so werden auch die Dauerheilungen häufiger werden; dies haben Bandelier und Pottenger schon bewiesen und vor kurzem auch ein frühercr Assistenzarzt von mir, Herr Dr. Kopp. Dieser konnte in seiner Inauguraldissertation (Beiträge zul Kasuistik der Tuberkulinbehandlung, Greifswald) bekannt geben, daß in letzter Zeit in der badischen Heilstätte Friedrichsheim durch das kombinierte Heilverfahren sehr günstige Resultate erzielt wurden: es wurden als arbeitsfähig entlassen $94 \%$ der Patienten, die mit Tuberkulin behandelt waren, gegenüber $79,7 \%$ im Jahre $1902,77,4 \%$ im Jahre 1901 und $74,2 \%$ im Jahre 1900 ohne Tuberkulinbehandlung; das kombinierte Verfahren hat eine Vermehrung der Heilerfolge um 14,3-19,8\% zur Folge gehabt. ${ }^{1}$ )

Ich kann mich denjenigen Aerzten nicht anschließen. welche die Pforten der Volksheilstätten auch den noch besserungsfähigen zweiten und dritten Stadien geöffnet wissen wollen; nach dem Gesetz sind die Landesversicherungsanstalten befugt, zur Abwendung des Anspruchs auf reichsgesetzliche Invalidenrente ein Heilverfahren in dem ihnen geeignet elscheinenden Umfang eintreten zu lassen, und auf Grund der heutigen wissenschaftlichen Anschauungen haben sie nur bei den ersten Stadien der Lungentuberkulose eine ziemlich sichere Aussicht, durch ein Heilverfahren dauernde und erhebliche Erwerbsfähigkeit wiederherzustellen; ich gebe zu, daß es immer wieder Fälle gibt, in welchen trotz ihrer Schwere unerwartete

1) Nach Fertigstellung dieser Arbeit ersah ich aus dem letzten Jahresbericht derselben Heilstätte, daß 1906 von den mit Tuberkulin Bebandelten dreimal soviel jhre Bazillon im Sputum verloren als von den Nichtgespritzten.
Wendungen zum Besseren eintreten, allein Ausnahmen bleiben diese immer. Wo soll auch die Versicherungsanstalt die Grenze ziehen? Wenn sie heute offiziell auch nur alle zweiten Stadien zuläßt - in Wirklichkeit kommen heute schon. viele zweite und dritte Stadien in die Heilstätten durch die verschiedene Beurteilung seitens der praktischen und der Heilstättenärzte - so würde eine Verzehnfachung sämtlicher Heilstätten nicht genügen, um diesem vermehrten Andrang zu entsprechen; hier muß die Unterstützung in obengenanntem Sinne von anderen Seiten kommen. Nur in einem Punkte hätte ich jetzt eine Bitte an die Versicherungsanstalten, und diese betrifft die Kinderfürsorge; die so überaus häufige latente Tuberkulose der Kinder, sei es, daß sie ihren Sitz in den Drüsen, Knochen oder Lungen hat, bietet ein äußerst günstiges Feld für das kombinierte Verfahren in den Heilstätten. Hier kann verhältnismäßig leicht und rasch im Keim unterdrückt werden, was später nur einem viel größeren Aufwand von Zeit und Mitteln weicht. Ich unterschätze keineswegs den Wert der Solbäder in der Behandlung der Drüsentuberkulose, eine Heilung wird durch sie jedoch in ausgesprochenen Fällen nicht erzielt. Nach $₹ 45$ des Invalidenversicherungsgesetzes können die Versicherungsanstalten etwaige Ueberschüsse des Sondervermögens im wirtschaftlichen Interesse der der Versicherungsanstalt angehörenden Rentenempfänger, Versicherten sowie ihrer Angehörigen verwenden. Wenn nun solche Anstalten, die dazu in der Lage sind, auf Grund dieses Paragraphen ihren bestehenden Heilstätten besondere Kinderabteilungen angliedern wiirden, was gewil ohne allzu große Kosten möglich wäre, so würden sic nicht nur ihre bisherigen großen Verdienste in der Tuberkulosebekämpfung um ein Beträchtliches vermehren, sondern sie wären auch in der Lage, durch Vernichtung der tuberkulösen Keime in den Drüsen und Knochen des jugendlichell Körpers den späteren Ausbruch der sekundären Lungentuberkulose überhaupt unmöglich zu machen.

Resümee : 1. Auf Grund von Heilversuchen an 25 Patienten mit Lungentuberkulose komme ich zu dem Schlusse, daß der Behandlung init Neutuberkulin der Vorzug zu geben ist. 2. Glaube ich annehmen zu können, daß manche bisher bekannt gegebenen Erfolge des Marmorekserums, besonders bei eiternden Fisteln, dem Gehalt des "Serum double“ an Streptococcenantitoxinen zuzuschreiben sind, nicht aber dem Gehalt an Heilstoffen gegen die Tuberkulose. 3. Dio Tuberkulinbehandlung der Lungentuberkulose, sowie der Drüsen- uno Knochentuberkulose im Kindesalter eröffnet günstige Ausblicke durch: a) Häusliche Behandlung mit Ausgang in Heilung vieler Patienten im latenten und ersten Stadium unter Zuhilfenahme von guter Pflege, Liegekuren im Freien und Landaufenthalt; b) Spitalbehandlung der noch besserungsfähigen zweiten und dritten Stadien in guten Tuberkulosekrankenhäusern der Städte; c) Entlastung der Volksheilstätten, welche durch obige Maßnahmen in den Stand gesetzt werden, eine größere Anzahl von Leichtkranken aufzunehmen und die bisher so ungünstige Wartezeit zu verkürzen; eine weitere Platzvermehrung in den Heilstätten wird dadurch entstehon, daß in Zukunft dann eine kürzere Behandlungsdauer von etwa acht bis zehn Wochen genügen wird, wenn die Patienten schon während der Wartezeit zu Hause oder im Krankenhaus mit Tuberkulin vorbehandelt sind; endlich wird eine in allen Heilstätten eingeführte Tuberkulinbehandlung die Rückfälle vermindern und damit durch Wegfall vieler Wiederholungskuren wieder neuen Patienten leichter und rascher eine erste Kur ermöglichen; d) Angliederung von Kinderstationen an die bestehenden Volksheilstätten, wo durch die kombinierte Behandlung in vielen Fällen dem Ausbruch der späteren Lungentuberkulose vorgebeugt werden kann. 